\title{
An Obligate Role for Oxygen in the Early Stages of Glutamate- Induced, Delayed Neuronal Death
}

\author{
Janet M. Dubinsky, ${ }^{1,2}$ Bruce S. Kristal, ${ }^{1}$ and Marta Elizondo-Fournier ${ }^{1}$ \\ 'Department of Physiology, University of Texas Health Science Center, San Antonio, Texas 78284-7756 and \\ ${ }^{2}$ Department of PHysiology, University of Minnesota, Minneapolis, Minneapolis 55455
}

\begin{abstract}
In vitro models of hypoxic/hypoglycemic injury reveal common mechanisms with glutamate excitotoxicity, but glutamate-induced toxicity in the absence of oxygen has never been directly addressed. Therefore, we assessed neuronal survival and intracellular calcium concentrations $\left(\left[\mathrm{Ca}^{2+}\right]\right.$ ) in neonatal hippocampal cultures in response to glutamate in the presence and absence of oxygen. Twenty-four hours of hypoxia alone killed $40 \%$ of the initial population, attributable to glutamate receptor-stimulated osmotic lysis. A 5 min glutamate exposure in ambient air killed $80 \%$ of the initial population by $24 \mathrm{hr}$ later. When cultures were deprived of oxygen during and for 2-24 hr after excitotoxin exposure, glutamate did not cause additional neuronal death beyond that induced by oxygen depletion alone. Toxicities caused by activation of NMDA, AMPA, or kainate receptors were each ameliorated by oxygen depletion. In the absence of oxygen, glutamate evoked normal increases in $\left[\mathrm{Ca}^{2+}\right]$, indicating that glutamate receptors functioned normally. The glutamate-induced increases in $\left[\mathrm{Ca}^{2+}\right]_{\text {, were not }}$ toxic in the absence of oxygen. In a similar manner, oxygen-depletion prevented neuronal killing by the calcium ionophore, ionomycin. Neuronal death produced by hydrogen peroxide or iron sulfate was not ameliorated by oxygen removal. These oxidants maximally produced only a slow increase in $\left[\mathrm{Ca}^{2+}\right]$, as the plasma membrane permeability increased nonspecifically. Therefore, oxygen-based reactions were an essential component of calcium-mediated, delayed neuronal death.
\end{abstract}

[Key words: excitotoxicity, neuronal death, glutamate, hypoxia, ischemia, glutamate receptors, oxygen]

Glutamate toxicity has been proposed as an underlying cause of neuronal death following stroke, ischemia, or traumatic brain injury (Tecoma et al., 1989; Lipton and Rosenberg, 1994). Microdialysis measurements detect elevated glutamate levels in the extracellular space during ischemia (Benveniste et al., 1984). In vitro, experimental hypoxic/hypoglycemic injury also produces elevated extracellular glutamate (Monyer et al., 1992) and can be prevented by antagonism of glutamate receptors (Rothman et al., 1987b; Sheardown et al., 1990; Kaku et al., 1991). Under in

Received Dec. 30, 1994; revised July 7, 1995; accepted July 13, 1995

J.M.D. and B.S.K. contributed substantially. We thank Dr. Steve Rothman for insightful discussions and for critical reading of the manuscript. This work was supported by NIA AG10034 and NIA T32AG00205.

Correspondence should be addressed to Janet M. Dubinsky, Ph.D., Department of Physiology, University of Minnesota, 6255 Millard Hall, 435 Delaware Street SE, Minneapolis, MN 55455.

Copyright $\odot 1995$ Society for Neuroscience $0270-6474 / 95 / 157071-08 \$ 05.00 / 0$ vitro conditions, overstimulation of glutamate receptors permits a massive influx of extracellular calcium that mediates a slowly progressive, delayed neurodegeneration (Choi, 1987; Rothman et al., 1987a).

However, in vitro glutamate toxicity has been studied under normal atmospheric oxygen, unlike the hypoxic environment present during the high glutamate associated with ischemia. Indeed, incomplete ischemia has been reported to be more damaging than complete ischemia in vivo (Hossmann and Kleihues, 1973), reducing measures of cerebral energy metabolism (Siesjo, 1981). This has led to the hypothesis that hypoxia may be protective against glutamate-receptor overstimulation (Choi, 1990). We have directly tested this hypothesis by examining the effects of oxygen deprivation on glutamate toxicity of cultured hippocampal neurons.

\section{Materials and Methods}

Tissue culture. Cultures of neonatal hippocampal neurons were prepared as described previously (Dubinsky, 1993). Cultures were maintained for two weeks in MEM without glutamine containing $27.75 \mathrm{~mm}$ glucose and $10 \%$ NuSerum (Collaborative Research). The high level of glucose used in these cultures was chosen (1) to provide sufficient glucose for extended culture periods without media replacement (Lopes-Cardozo et al., 1986), (2) to minimize the damaging effects of hypoxia itself (Tombaugh and Sapolsky, 1990), and (3) to possibly stimulate glycolysis via the Crabtree effect (Crabtree, 1929) so that hypoxia would not produce major shifts in energy metabolism.

Toxicity experiments. Unless otherwise specified, cultures were challenged by exposure to $500 \mu \mathrm{M}$ glutamate for $5 \mathrm{~min}$, rinsed in Earle's Balanced Salt Solution, and incubated at $37^{\circ} \mathrm{C}$ for $24 \mathrm{hr}$. Cell survival was assessed by counting preselected fields after trypan blue exclusion (Dubinsky, 1993). Cells were bathed in the following solutions: during the five minutes of glutamate exposure, Earle's MEM supplemented with $26 \mathrm{~mm} \mathrm{NaHCO}, 100 \mu \mathrm{M}$ glutamine, $10 \mu \mathrm{M}$ glycine, $27.75 \mathrm{~mm}$ glucose, $35 \mathrm{~mm}$ sucrose, $\mathrm{pH} 7.4,352 \mathrm{mOsm}$; during the $24 \mathrm{hr}$ incubation period, Earle's balanced salt solution containing $116 \mathrm{~mm} \mathrm{NaCl}, 5.4 \mathrm{~mm}$ $\mathrm{KCl}, 1.8 \mathrm{mM} \mathrm{CaCl}_{2}, 0.8 \mathrm{M} \mathrm{MgSO}_{4}, 1 \mathrm{mM} \mathrm{NaH}_{2} \mathrm{PO}_{4}, 26.2 \mathrm{mM} \mathrm{NaHCO}_{3}$,


$100 \mu \mathrm{M}$ glutamine during the $24 \mathrm{hr}$ incubation did not increase hypoxiainduced neuronal killing (Goldberg et al., 1988). Experiments minimizing osmotic lysis were performed in a solution composed of (in $\mathrm{mm}$ ): $116 \mathrm{NaGluconate,} \mathrm{5.4} \mathrm{KGluconate,} 5.3 \mathrm{CaCl}_{2}, 1.3 \mathrm{MgSO}_{4}, 27.7$ glucose, 35 sucrose, $26.2 \mathrm{NaHCO}_{3}, 1 \mathrm{NaH}_{2} \mathrm{PO}_{4}$. The added calcium and magnesium concentrations were adjusted to theoretically yield $1.8 \mathrm{~mm}$ free calcium and $0.8 \mathrm{~mm}$ free magnesium concentrations in the presence of gluconate. These were calculated using gluconate $\log \mathrm{K}^{\prime}$ for $\mathrm{Ca}^{2+}$ and $\mathrm{Mg}^{2+}$ of 1.21 and 0.70 , respectively (Handbook of Chemistry and Physics, 40th ed., CRC, 1958). Unless otherwise specified, all toxicity data a compilation of three cultures per condition from each of three replicate experiments.

For toxicity experiments, cells exposed to ambient air $/ 5 \% \mathrm{CO}_{2}$ were handled on the bench top for glutamate application followed by incubation at $37^{\circ} \mathrm{C}$ in $95 \%$ air, $5 \% \mathrm{CO}_{2}$ for $24 \mathrm{hr}$. All solutions were warmed and equilibrated with $95 \%$ air, $5 \% \mathrm{CO}_{2}$. In control experiments, toxicity 
was equivalent for solutions actively equilibrated by bubbling with gas or for solutions passively equilibrated in a $5 \% \mathrm{CO}_{2}$ incubator.

Cells exposed to hypoxia were manipulated in a sealed plastic glove bag inflated with $95 \% \mathrm{~N}_{2}, 5 \% \mathrm{CO}_{2}$ and were rinsed in solutions equilibrated with $95 \% \mathrm{~N}_{2}, 5 \% \mathrm{CO}_{2}$ (actively bubbled). Atmosphere inside the bag was flushed at least three times (vacuum extraction followed by $95 \% \mathrm{~N}_{2}, 5 \% \mathrm{CO}_{2}$ influx at $5-10$ psi) until a miniature oxygen electrode (Microelectrodes, Inc.) placed inside the bag registered an oxygen content of $\leq 1.0 \%$ (average $0.0 \pm 0.2$ in 16 experiments). In several experiments, the calibration range on the oxygen electrode was extended to twice normal to insure that the oxygen readings in this low range were reliable. Inflating the hag with $95 \%$ argon, $5 \% \mathrm{CO}$, resulted in identical toxicity, ruling out nitrogen specific effects.

For long term incubations in the hypoxic environment, uncapped culture dishes and the $\mathrm{O}_{2}$ electrode and meter were placed inside the in cubator at $37^{\circ} \mathrm{C}$ in an airtight chamber (Billups-Rothenberg Inc., Del Mar CA) filled with $95 \% \mathrm{~N}_{2}, 5 \% \mathrm{CO}_{2}$. After $24 \mathrm{hr}$, oxygen levels in the chamber remained below $1.0 \%$, averaging $0.3 \pm 0.3 \%(N-18$ experiments). In two experiments, oxygen content of the solutions over the cells was measured as $0.8 \pm 0.08 \%(N=18)$ during glutamate, 0.4 $\pm 0.05 \%$ at the beginning of the incubation period, and $0.1 \pm 0.06 \%$ at the end of the $24 \mathrm{hr}$ of hypoxia. In one experiment, $\mathrm{pH}$ measurements were made in cultures $24 \mathrm{hr}$ after toxic exposure. Cultures were removed from the incubator and immediately encased, along with the $\mathrm{pH}$ meter, in the glove bag which was then inflated with either $95 \%$ air, $5 \%$ $\mathrm{CO}_{2}$ or $95 \% \mathrm{~N}_{2}, 5 \% \mathrm{CO}_{2}$

Calcium measurements. The fluorescence microscope and low light level detector system (Hartley and Dubinsky, 1993) were encased in the plastic glove bag along with the oxygen electrode and meter. Cultures incubated with $4 \mu \mathrm{M}$ fura-2-AM for 15 min were rinsed in a basic salt solution (containing in mM: $139 \mathrm{NaCl}, 3 \mathrm{KCl}, 1.8 \mathrm{CaCl}_{2}, 0.8 \mathrm{MgCl}_{2}$, 10 NaHEPES, 27.75 glucose, 15 sucrose, 0.01 glycine, $\mathrm{pH} 7.4,330$ mOsm), and placed on the microscope stage. Camera gains and a neuronal field were selected for monitoring. The bag was sealed and the atmosphere was changed to one containing $95 \% \mathrm{~N}_{2}, 5 \% \mathrm{CO}_{2}$, by successive application of vacuum and entry of the nitrogen gas mixture. Four to five cycles of gas exchange were required $(30-60 \mathrm{~min})$ to reach an oxygen level of $\leq 0.5 \%$. This was maintained without decrement until the bag was opened. During the first entry of the nitrogen atmosphere, the solution bathing the cells was changed to one equilibrated with $95 \% \mathrm{~N}_{2}, 5 \% \mathrm{CO}_{2}$ (in mM: $114 \mathrm{NaCl}, 3 \mathrm{KCl}, 1.8 \mathrm{CaCl}_{2}, 0.8 \mathrm{MgCl}_{2}$, $26 \mathrm{NaHCO}_{3}, 27.75$ glucose, 15 sucrose, 0.01 glycine, $\mathrm{pH} 7.4,333$ mOsm). Control experiments were performed in an identical manner but the bag was gassed (four exchanges) with $95 \%$ air, $5 \% \mathrm{CO}_{2}$.

Calcium concentrations were assessed using ratios of the emitted fluorescence $(530 \pm 15 \mathrm{~nm})$ upon stimulation at $340 \pm 10 \mathrm{~nm}$ and 380 $\pm 10 \mathrm{~nm}$ (Grynkiewicz et al., 1985). Calibrations were performed in situ by exposing untreated neurons to $5 \mu \mathrm{M}$ ionomycin in the bicarbonate buffered salt solution (above) in $95 \%$ air, $5 \% \mathrm{CO}_{2}$ followed by addition of $15 \mathrm{mM} \mathrm{K} \mathrm{K}_{2}$ EGTA. Resulting values of $R_{\max }, R_{\min }$, and $\beta$ are indicated in the figure captions.

Basal $\left[\mathrm{Ca}^{2+}\right]_{i}$ after a $24 \mathrm{hr}$ hypoxic and/or toxic exposure was monitored by loading dishes in $95 \%$ air, $5 \% \mathrm{CO}_{2}, 37^{\circ} \mathrm{C}$, with fura-2-AM. These measurements were necessarily made in ambient air after removal from the hypoxic chamber or ambient air incubator and assessment of survival. Cells were bathed in (in $\mathrm{mM}$ ); $139 \mathrm{NaCl}, 3 \mathrm{KCl}, 1.8 \mathrm{CaCl}_{2}$, $0.8 \mathrm{MgCl}_{2}, 1.0 \mathrm{NaHCO}_{3}, 27.75$ glucose, 15 sucrose, $10 \mathrm{NaHEPES}$, and 0.01 glycine. Intracellular calcium responses to $\mathrm{H}_{2} \mathrm{O}_{2}$ and iron sulfate in naive cultures were also determined in ambient air in this HEPES buffered solution.

\section{Results}

Toxicity studies were performed upon cultured hippocampal neurons in ambient air $/ 5 \% \mathrm{CO}_{2}$, or an hypoxic environment of $95 \% \mathrm{~N}_{2}, 5 \% \mathrm{CO}_{2}$. Neuronal exposure to the hypoxic environment for 5 min produced little cell death by itself but exposure to the hypoxic environment for $24 \mathrm{hr}$ killed about $40 \%$ of the initial population (Fig. IA). Although not studied in detail, shorter hypoxic exposures produced less cell death. No damage to the astrocyte feeder layer was currently observed, in agreement with several laboratories (Vibulsreth et al., 1987; Goldberg et al., 1988; but see Yu et al., 1989). Five minute exposure to 500 $\mu \mathrm{M}$ glutamate was equally toxic in either ambient air or hypoxic
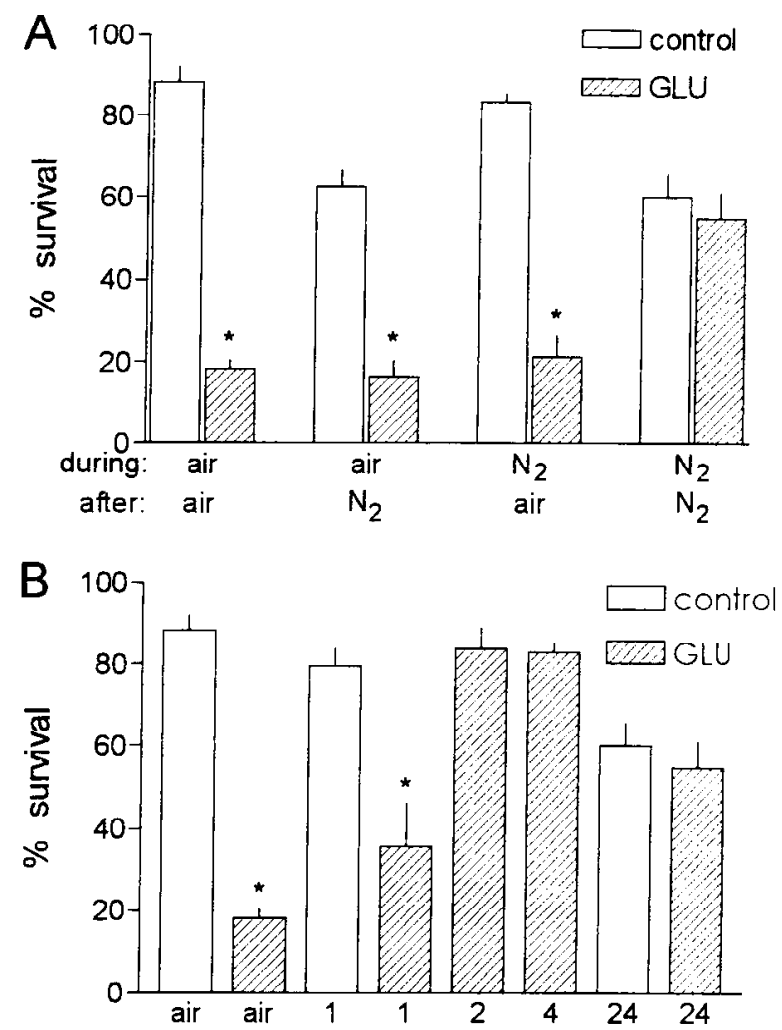

Figure 1. Oxygen depletion during and after glutamate overexposure was neuroprotective. $A$, Survival of neurons maintained in the indicated atmospheres for the $5 \mathrm{~min}$ glutamate exposure (during) and the following $24 \mathrm{hr}$ period (after). Hatched bars represent cultures exposed to glutamate. Open bars represent cultures receiving only solution changes as controls. Mean \pm SEM for 12-18 cultures per condition. Unless otherwise specified, statistical comparisons (one-way ANOVA followed by Bonferroni multiple comparisons test) were made between test conditions and the control bar to their immediate left. Asterisk indicates $p$ $<0.001 . B$, Oxygen removal during glutamate exposure and for as little as $2 \mathrm{hr}$ afterwards protected hippocampal neurons. Numbered bars represent the number of hours after glutamate treatment that cultures remained in the oxygen-depleted environment before reintroduction of ambient air. Bars labeled air represent cultures handled in ambient air/ $5 \% \mathrm{CO}_{2}$. All cultures were counted $24 \mathrm{hr}$ following glutamate exposure.

environments if followed by recovery in ambient air. Likewise, glutamate exposure in air followed by the presence or absence of oxygen resulted in identical toxicity.

In contrast, removal of oxygen during both the glutamate challenge and the recovery period resulted in no additional cell loss beyond that induced by the hypoxic environment alone (Fig. $1 A$ ). Changes in the culture environment as a consequence of the extended hypoxia could not account for the observed protection. After $24 \mathrm{hr}$, lactate levels rose to $1.12 \pm 0.04 \mathrm{mM}$ in air and $1.21 \pm 0.09$ in the nitrogen environment (mean \pm SEM. $N$ $=9$, not significantly different, two-tailed $t$ test). These appeared to be well buffered as the color of the phenol red indicator did not change noticeably. $\mathrm{pH}$ of the culture media $24 \mathrm{hr}$ after toxicity was $7.32 \pm 0.003$ in cultures exposed to glutamate in ambient atmosphere and $7.39 \pm 0.002$ in cultures exposed to glutamate and maintained in oxygen-depleted atmosphere $(n=12$, $p<0.0001$, two-tailed $t$ test). In the absensce of lactate accumulation, it is difficult to ascribe the observed protection to a minor alkaline shift in external pH (see Discussion).

Further experiments showed oxygen removal during and for as little as $2 \mathrm{hr}$ after glutamate exposure was sufficient to pro- 

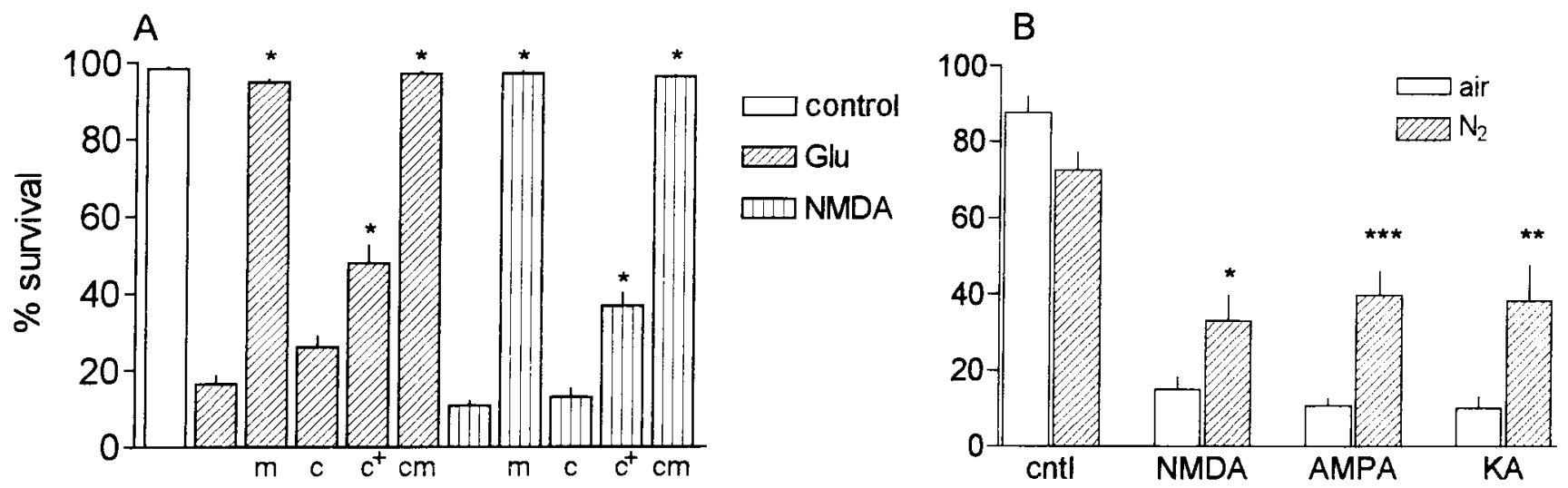

Figure 2. A, Both NMDA and non-NMDA receptors contribute to excitotoxic death. Hippocampal cultures received 5 min exposure to either 500 $\mu \mathrm{M}$ glutamate (hatched bars) or $500 \mu \mathrm{M}$ NMDA (striped bars) accompanied by $20 \mu \mathrm{M}$ MK-801 (m), $20 \mu \mathrm{M}$ CNQX (c), or $20 \mu \mathrm{M}$ MK-801 and $20 \mu \mathrm{M}$ CNQX $(\mathrm{cm})$. An additional set of cultures received $20 \mu \mathrm{M}$ CNQX both during toxin cxposurc and for the subsequent $24 \mathrm{hr}\left(c^{+}\right)$. Asterisks indicate $p<0.001$ when compared to agonist alone. $B$. Oxygen removal partially protected against cell killing produced by different paradigms of glutamate receptor stimulation. Toxic exposures consisted of $N M D A: 5$ min of $500 \mu \mathrm{M}$ NMDA followed by rinse in Earles' Balanced Salt Solution; AMPA: $24 \mathrm{hr}$ of $30 \mu \mathrm{M}$ AMPA plus $20 \mu \mathrm{M}$ MK-801; KA: $24 \mathrm{hr}$ of $30 \mu \mathrm{M}$ kainate plus $20 \mu \mathrm{M} \mathrm{MK}-801$. Bars represent 12-15 cultures per condition from five experiments. Statistical comparisons were made between toxic insults delivered in ambient air (open bars) and those in $95 \% \mathrm{~N}_{2}, 5 \% \mathrm{CO}_{2}$ (hatched bars) as described above. ${ }^{*}, p<0.05 ;{ }^{* *}, p<0.01 ; * *, p<0.001$.

duce maximum protection (Fig. $1 B$ ). Reintroduction of oxygenated atmosphere after $1-4 \mathrm{hr}$ of hypoxia by itself did not produce additional injury. Extending the hypoxia bcyond $2 \mathrm{hr}$ imposed additional cell killing attributable to oxygen depletion alone. Thus, oxygen availability during an initial critical period appears to play an obligate role in subsequent glutamate-induced injury.

Activation of different subtypes of ionotropic glutamate receptors each contribute to excitotoxic death, possibly by different mechanisms (Koh et al., 1990). MK-801, a noncompetetive NMDA antagonist, completely blocked toxicity induced by either glutamate or NMDA (Fig. 2A). CNQX, at concentrations that competetively inhibit non-NMDA receptors (Yamada et al., 1989), did not prevent toxicity when present during glutamate or NMDA exposure. However, when present both initially and during the $24 \mathrm{hr}$ recovery period, CNQX was neuroprotective (Fig. $2 A$ ). Thus, while NMDA receptor activation was the primary event, non-NMDA receptor activation contributed to secondary toxic processes that occurred following both glutamate and NMD $\Lambda$ overexposures.

Two different paradigms were employed to test the oxygen sensitivity of the toxicity produced by activation of each of these receptor subtypes. Transient NMDA receptor overstimulation mimicked the primary event in glutamate toxicity (Rothman and Olney, 1986) and long, low level activation of AMPA or KA receptors mimicked the slowly progressive neuronal death (Koh et al., 1990). Oxygen removal during and after NMDA exposure improved survival (Fig. 2B). Oxygen removal during $24 \mathrm{hr}$ exposures to low doses of KA or AMPA provided greater, partial protection. Thus there appeared to be an oxygen dependent component to the excitotoxicity produced by activation of each type of ionotropic receptor.

One mechanism that must be considered to underlie any protective treatment is direct glutamate receptor antagonism. To assess glutamate receptor function in the absence of oxygen, glutamate-induced calcium increases were monitored in fura-2-AM loaded neurons during bath application of glutamate (Dubinsky, 1993). Glutamate receptor stimulation in the hypoxic atmosphere produced a rise in $\left[\mathrm{Ca}^{2+}\right]_{i}$ that closely resembled that produced in ambient air (Fig. 3). $\left[\mathrm{Ca}^{2+}\right]_{i}$ in both atmospheres rose rapidly to an initial peak and then decayed slowly towards basal levels. Half of all neurons monitored in either atmosphere displayed a plateau on the falling phase of the $\left[\mathrm{Ca}^{2+}\right]_{i}$ changes, suggestive of the patterns attributed to mitochondrial sequestration and release in DRG neurons (Friel and Tsien, 1994; Werth and Thayer, 1994). Thus, glutamate receptor activation remained intact in the absence of oxygen.

Long term, permanent shifts in basal $\left[\mathrm{Ca}^{2+}\right]_{i}$ were also not observed with the prolonged hypoxic treatments. No differences were observed in resting $\left[\mathrm{Ca}^{2+}\right]_{i}$ between cultures protected from delayed, calcium-mediated glutamate toxicity by hypoxia and control cultures receiving similar solution changes but incubated in $95 \%$ air, $5 \% \mathrm{CO}_{2}$ for $24 \mathrm{hr}$ (ratios of $0.296 \pm 0.009, \mathrm{~N}=$ 110 from three dishes after hypoxia vs $0.294 \pm 0.008, N=128$ from three dishes in controls, n.s. two-tailed $t$ test). Neurons removed from hypoxic environments responded to glutamate with appropriate increases in $\left[\mathrm{Ca}^{2+}\right]_{i}$.

Extended periods of oxygen deprivation killed approximately $40 \%$ of the initial neuronal population. This might be attributable to loss of metabolic energy production (Siesjo, 1981; Kass and Lipton, 1982) or to indirect glutamate receptor activation as observed with combined hypoxic/hypoglycemic models of in vitro neuronal death (Goldberg et al., 1987, 1988; Tombaugh and Sapolsky, 1990). Glucose levels declined to $26.8 \pm 0.1 \mathrm{mM}(N=6)$ by the end of $24 \mathrm{hr}$ in air and $24.9 \pm 0.2 \mathrm{mM}(N=9)$ in nitrogen $(p<0.0001$, two-tailed $t$ test). Further increasing the glucose concentration in the medium failed to protect against the hypoxic cell loss $(77.1 \pm 2.5 \%$ survival, $N=6$ in $40 \mathrm{mM}$ glucose compared to $75.0 \pm 2.0 \% N=6$ in $27.75 \mathrm{~mm}$ glucose, n.s. Student-NewmanKeuls). Thus despite the increased consumption during hypoxia, glucose availability was not a limiting factor for survival during hypoxia in these experiments. Addition of other possible energy sources, $10 \mathrm{Im}$ pyruvate or $20 \mathrm{~mm}$ fructose, were also not protective against the extended hypoxia $(81.1 \pm 3.6 \%$ survival $N=6$, pyruvate; $75.0 \pm 1.9 \% N=6$, fructose, n.s.).

In contrast, glutamate receptor antagonists, MK-801 and/or CNQX added at the time of oxygen depletion prevented the cell loss associated with severe hypoxia (Fig. 4A). Since oxygen depletion did not noticeably alter basal $\left[\mathrm{Ca}^{2+}\right]_{i}$ during the initial 

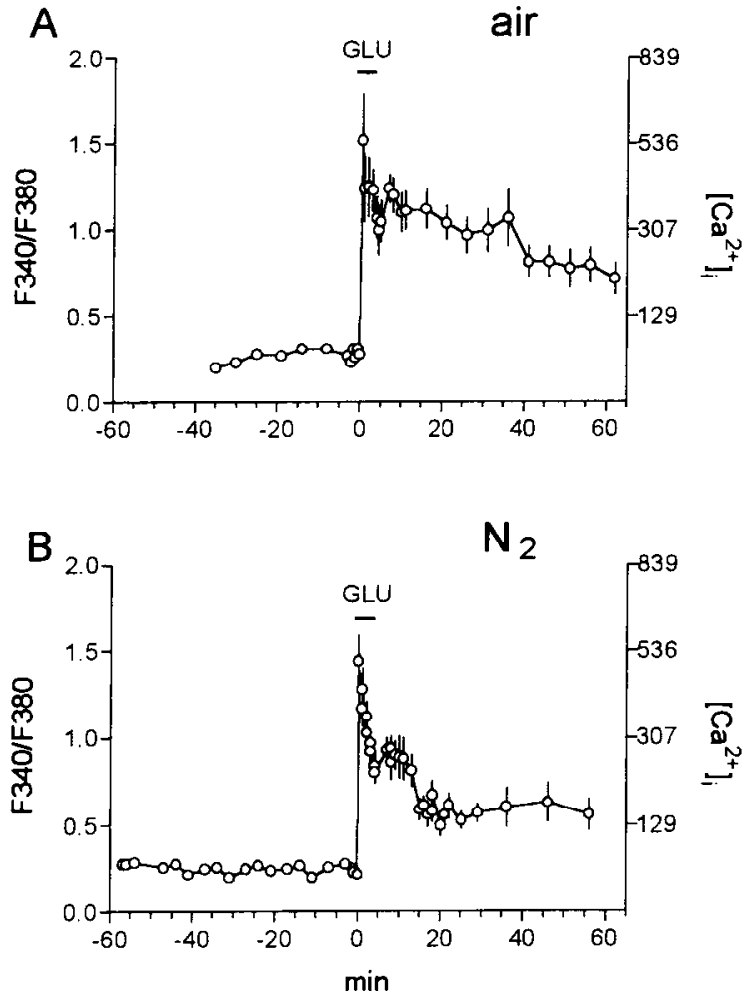

Figure 3. Similar intracellular calcium changes were induced by glutamate receptor activation in either the presence $(95 \%$ air, $5 \% \mathrm{CO}, A)$ or absence $\left(95 \% \mathrm{~N}_{2}, 5 \% \mathrm{CO}_{2}, B\right)$ of oxygen (11). $\left[\mathrm{Ca}^{2+}\right]_{i}$ was monitored every 5 min during the changes in atmosphere prior to glutamate application (horizontal line). Statistical comparisons were made only be tween those data points that were acquired synchronously in both $A$ and $B$. Data points at $0,0.5,1,4,5,10,11,16,21,26,31,36,46$, and 56 min were compared, pairwise, by Student's $t$ test. Only those points at 16,21 , and $26 \mathrm{~min}$ were significantly different at the $p<0.05 \%$ level. Data represent 35 neurons from three experiments in $A$ and 24 neurons from three experiments in $B . R_{\max }, R_{\min }$, and $\beta$ were $5.10,0.06$, and 5.99 , respectively.

hour (Fig. $3 B$ ) or after 24 hr of hypoxia, calcium-independent mechanisms were considered. NMDA receptor overstimulation results in osmotic lysis following uninterrupted cation influx through open receptors, and the consequent passive $\mathrm{Cl}^{-}$and $\mathrm{H}_{2} \mathrm{O}$ entry (Rothman, 1985). Therefore, cultures were made hypoxic in solutions containing very low concentrations of $\mathrm{Cl}^{-}$to prevent osmotic swelling (Rothman, 1985; Friedman and Haddad, 1994). Under these conditions, no cell death was observed (Fig. 4B). Thus, hypoxia alone appeared to produce a low level of extracellular glutamate accumulation that caused a slowly progressive neuronal death via osmotic lysis.

To eliminate the contribution of osmotically driven neuronal death, experiments were performed exposing cultures to different toxic doses of glutamate in the low chloride solutions (Fig. 5). Oxygen depletion during and for $24 \mathrm{hr}$ after glutamate exposure fully protected these cultures against the remaining calcium-mediated degeneration. There was however, one exception. Prolonging the dose of glutamate to $30 \mathrm{~min}$ evidently produced neuronal damage that was too severe to be totally ameliorated by hypoxia. Thus, there appear to be extreme conditions in which the glutamate receptor mediated processes can be toxic without a contribution from oxygen-based reactions.

The relationship between calcium and oxygen dependence of neurotoxicity was explored by exposing cultures to a variety of
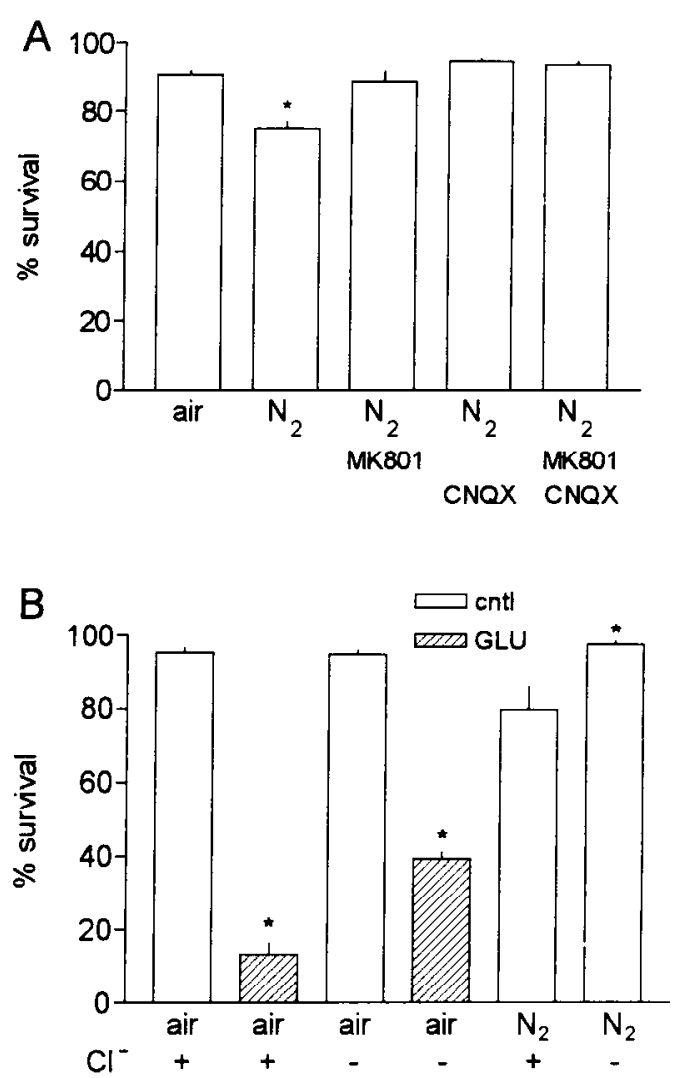

Figure 4. Neurotoxicity induced by $24 \mathrm{hr}$ of severe hypoxia was attributable to low level glutamate receptor activation. $A$, Glutamate receptor antagonists, $20 \mu \mathrm{M}$ MK801, $20 \mu \mathrm{M}$ CNQX, or their combination prevented toxicity in cultures maintained for $24 \mathrm{hr}$ in the hypoxic environment $\left(\mathrm{N}_{2}\right)$. Statistical comparisons were made between each oxygen-depleted condition and the air control using Dunnett's test. Asterisk indicates $p<0.01$. $B$, Low chloride solutions ameliorated glutamateinduced toxicity in air and prevented toxicity associated with $24 \mathrm{hr}$ of hypoxia. Statistics as in Figure $1 A$.



Figure 5. Oxygen depletion protected against more severe, calciumdependent glutamate insults. Protection against prolonged glutamate exposures was substantial but less complete. Hippocampal cultures were exposed to $0.5 \mathrm{~mm}$ or $5 \mathrm{~mm}$ glutamate for the indicated times in ambient air (open bars) or in $95 \%$ argon, $5 \% \mathrm{CO}_{2}$ (hatched bars) and maintained in that atmosphere for $24 \mathrm{hr}$. These experiments were performed in low chloride solutions. Statistical comparisons were performed as described in Figure $1 A$. 


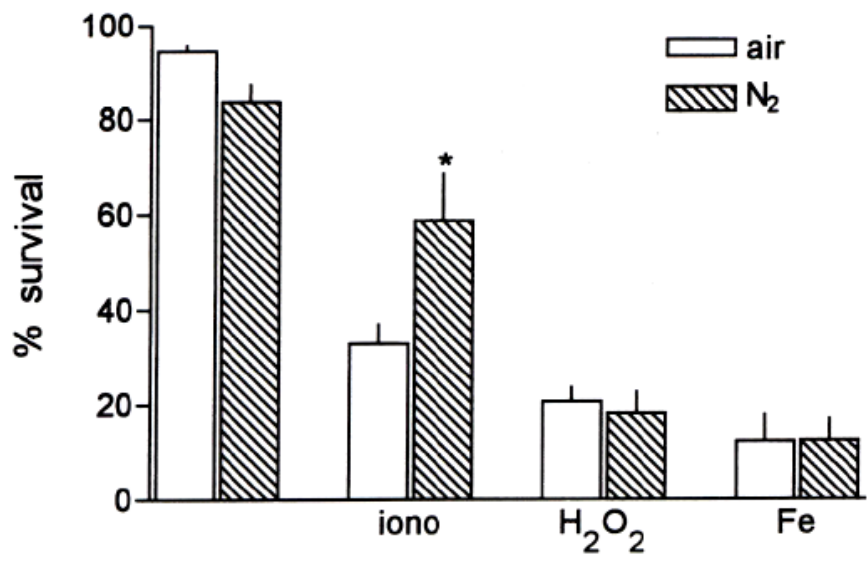

Figure 6. Oxygen depletion during and for $24 \mathrm{hr}$ after $5 \mathrm{~min}$ exposure to other toxic agents provided partial protection against $1 \mu \mathrm{M}$ ionomycin (iono), but not $1 \mathrm{mM} \mathrm{H} \mathrm{H}_{2}\left(\mathrm{H}_{2} \mathrm{O}_{2}\right)$ or a combination of $50 \mu \mathrm{M}$ ferric sulfate, $50 \mu \mathrm{M}$ ferrous sulfate and $1 \mathrm{~mm}$ ascorbate $(\mathrm{Fe})$. agents. To test if these additional forms of toxicity also involved oxygen-based processes, we exposed hippocampal cultures in the presence and absence of oxygen to (1) ionomycin, a calcium ionophore; (2) hydrogen peroxide, an exogenous, highly reactive oxygen species; or (3) a mixture of ferric and ferrous sulfate and ascorbic acid, a potent oxidant combination (Fig. 6). Application of $\mathrm{H}_{2} \mathrm{O}_{2}$ and iron sulfate were equally toxic in ambient air or hypoxic atmospheres (Fig. 6). Oxygen was apparently not required for the toxicity initiated by these highly reactive compounds. Oxygen depletion did protect against ionomycin-induced cell death (Fig. 6).

These other toxic agents produced very different intracellular calcium responses from that of glutamate. Ionomycin application is widely used to produce an uncontrolled calcium influx and maximal increases in $\left[\mathrm{Ca}^{2+}\right]_{i}$. It is commonly applied to calibrate fura-2 fluorescence ratios (Grynkiewicz et al., 1985). In contrast, $\mathrm{H}_{2} \mathrm{O}_{2}$ and iron sulfate did not produce large initial, transient increases in $\left[\mathrm{Ca}^{2+}\right]_{i}$ like glutamate or ionomycin (Fig. 7). Five minute application of $\mathrm{H}_{2} \mathrm{O}_{2}$ produced only minor perturbations
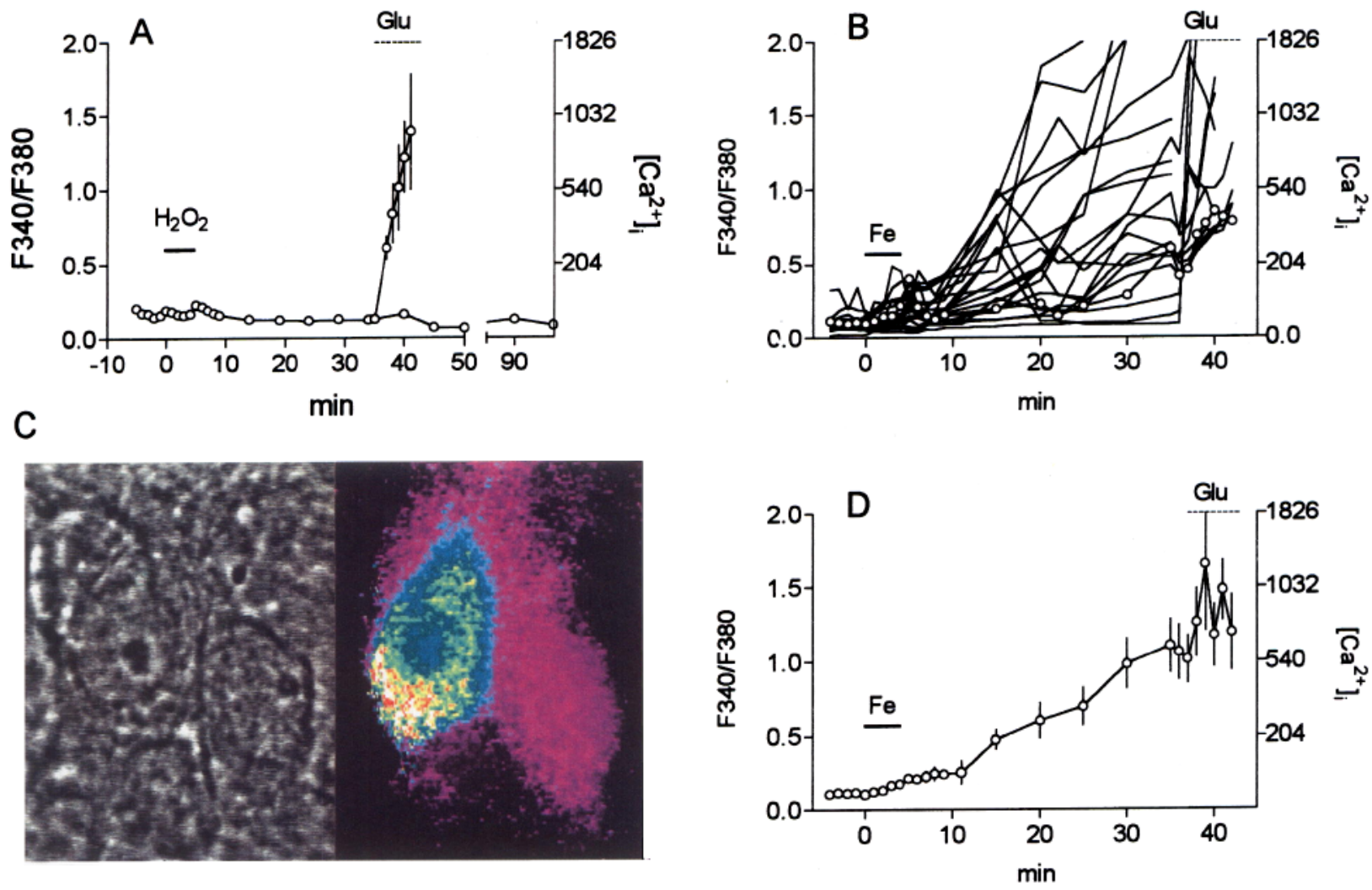

Figure 7. Fura-2 fluorescence responses to hydrogen peroxide $(A)$ and a combination of $50 \mu \mathrm{M}$ ferric sulfate, $50 \mu \mathrm{M}$ ferrous sulfate and $1 \mathrm{mM}$ ascorbate $(B, D)$. A, Five minutes of $1 \mathrm{mM} \mathrm{H}_{2} \mathrm{O}_{2}$ produced no changes in $\left[\mathrm{Ca}^{2+}\right]_{i}$ in 17 hippocampal neurons from three dishes. In one experiment (five neurons), $\left[\mathrm{Ca}^{2+}\right]_{i}$ remained stable for over $90 \mathrm{~min}$. In another experiment (eight neurons), $500 \mu \mathrm{M}$ glutmate (dotted line) was added after 35 min. $B$ and $D$, Five minutes of the iron sulfate mixture produced a slow rise in $\left[\mathrm{Ca}^{2+}\right]_{i}$ in 20 neurons from three dishes. Thirty-seven minutes later, responses to $500 \mu \mathrm{M}$ glutamate varied greatly (13 neurons). The highly variable responses of individual neurons are shown in $B$ and the average response appears in $D$. Circles indicate the times ratios were acquired. In $B$, note that only those neurons with the lowest $\left[\mathrm{Ca}^{2+}\right]_{i}$ demonstrated a clear response to glutamate. $C$, Ratio image of two neurons' response to iron revealed an initial increase in cytoplasmic $\left[\mathrm{Ca}^{2+}\right]_{i}$ prior to nuclear calcium changes. The ratio image was taken at $20 \mathrm{~min}$. By the time the bright-field image was taken, 25 min later, a prominent membrane bleb had developed in the plasma membrane of the leftmost neuron and dye had disappeared from the soma. Pseudocolor scale range is identical to the $\mathrm{y}$-axis scale; black to red correspond to ratios of $0-2$. In these experiments, $R_{\max }, R_{\min }$, and $\beta$ were $3.6,0.09$, and 6.97 , respectively. 
in $\left[\mathrm{Ca}^{2+}\right]_{i}$ for at least $90 \mathrm{~min}$ afterwards (Fig. 7A). Intracellular calcium in these neurons did rise sharply in response to subsequent glutamate addition. Higher concentrations of $\mathrm{H}_{2} \mathrm{O}_{2}$ produced slowly increasing cytoplasmic calciums accompanying somal swelling in a manner similar to iron.

The iron sulfate mixture caused a slowly progressive increase in $\left[\mathrm{Ca}^{2+}\right]_{i}$ that was quite variable in its onset and rate of increase (Fig. $7 B, C$ ). When $\left[\mathrm{Ca}^{2+}\right]_{i}$ did rise, it never seemed to plateau or recover. The increase in $\left[\mathrm{Ca}^{2+}\right]_{i}$ was accompanied by an overall decrease in intensity of fura- 2 fluorescence when stimulated at both 340 and $380 \mathrm{~nm}$. This often required continually increasing the camera gain to maintain realistic ratio values. Once $\left[\mathrm{Ca}^{2+}\right]_{i}$ began to rise, neuronal somas also became noticably swollen or blebbed. In a few flat neurons, the increase in $\left[\mathrm{Ca}^{2+}\right]_{i}$ appeared first in a crescent at the edge of the soma, then filled cytoplasmic areas (Fig. 7D), and only later spread throughout the nucleas as well. When glutamate was subsequently added to these cultures, responses were not always distinguishable from the already steadily increasing $\left[\mathrm{Ca}^{2+}\right]_{i}$. These observations could be explained by a slowly progressive nonspecific increase in permeability of the plasma membrane which would let external calcium enter the cell while the fura- 2 dye exitted. Thus iron sulfate appeared to act by directly damaging the neuronal plasma membrane. The hydrogen peroxide and iron sulfate toxicities were not associated with an early transient increase in $\left[\mathrm{Ca}^{2+}\right]_{i}$ nor were they prevented by oxygen depletion. Ionomycin toxicity, as well as glutamate toxicity, required oxygen in addition to the influx of extracellular calcium.

\section{Discussion}

Our data demonstrates that delayed, calcium-mediated neuronal death requires the presence of oxygen. This was true when either glutamate or ionomycin were the toxins. In the case of glutamate, oxygen was required either during initial exposure or within a critical period of approximately $2 \mathrm{hr}$ after glutamate removal. In the absence of oxygen, the changes initiated by disturbances in intracellular calcium homeostasis appeared insufficient to produce neuronal death.

The relative contributions of elevated $\left[\mathrm{Ca}^{2+}\right]_{i}$ and oxygenbased reactions towards eventual toxicity can not be separated in the current set of experiments. The data demonstrate that the initial peak $\left[\mathrm{Ca}^{2+}\right]_{i}$ values and the time course of recovery were largely similar during glutamate treatments in both aerobic and anaerobic atmospheres. This is consistent with the lack of correlation between peak $\left[\mathrm{Ca}^{2+}\right]_{i}$ and eventual neuronal death (Michaels and Rothman, 1990; Randall and Thayer, 1992). At intermediate periods, some small differences were noted. No data are available concerning the relationship of $\left[\mathrm{Ca}^{2+}\right]_{i}$ in this time period with eventual death, although a relationship between toxic outcome and the duration of calcium elevation has been suggested (Ogura et al., 1988). Further experiments are necessary to determine if the hypoxic protection results from an acceleration of calcium recovery.

Extended periods of glutamate receptor activation were able to overcome the protection provided by the anerobic environment. This observation is consistent with the notion that neuronal death can be produced by multiple glutamate-triggered pathways (Dubinsky et al., 1995), only some of which require oxygen. Multiple oxygen-based steps may contribute to the eventual toxicity since oxygen depletion provided full protection whereas blockade of calcium-stimulated enzyme reactions only provides partial protection (Rothman et al., 1993; Zhang et al., 1994).

Multiple processes certainly contribute to excitotoxicity since different types of glutamate receptors were activated at different times. Initial blockade of NMDA receptors provided full protection confirming that NMDA receptor activation was the primary toxic event. Continuous blockade of non-NMDA receptors also protected significantly indicating that they contribute to secondary excitotoxic processes. Oxygen-deprivation significantly improved survivals in paradigms mimicking this secondary process. Oxygen-deprivation was also effective in protecting against short term NMDA receptor overstimulation. Transient NMDA receptor overactivation is thought to result in death by a combination of rapid osmotic mechanisms and delayed calcium-mediated pathways (Rothman and Olney, 1986). In the NMDA experiments, the osmotic destabilization may have contributed to the overall neuronal death in addition to the calcium-mediated pathways. Thus the efficacy of oxygen-deprivation in preventing glutamate-induced toxicity probably represents a combined interruption of multiple pathways.

Hypoxia alone produced neuronal cell loss, attributable to glutamate-receptor stimulated osmotic lysis. Hypoxia did not produce short term or permanent increases in $\left[\mathrm{Ca}^{2+}\right]_{i}$. This is in contrast to reports to the contrary after prolonged hypoxic exposures for $\left[\mathrm{Ca}^{2+}\right]_{i}$ in freshly dissociated adult hippocampal neurons (Friedman and Haddad, 1993). Chronological age of the neurons and the acute nature of the latter preparation may account for this difference. Contrasts between the current result and the ${ }^{45} \mathrm{Ca}$ accumulation observed in hypoxic cortical cultures may reflect the differences between fura- 2 and ${ }^{45} \mathrm{Ca}$ measurements throughout the excitotoxicity literature (Marcoux et al., 1990). Cellular energy requirements under severe hypoxia were presumably met by the high rate of glycolytic metabolism in cultured neurons (Pauwels et al., 1985; Lopes-Cardozo et al., 1986). Combined hypoxia/hypoglycemia-induced neuronal death and neuronal death induced by hypoxia alone have been attributed to activation of glutamate-based toxicity mechanisms (Goldberg et al., 1988; Kaku et al., 1991). In addition, hypoxic pretreatments predispose neuronal cultures to increased glutamate toxicity when the intervening period is relatively short (Kohmura et al., 1990; Dubinsky, 1992).

Many important cellular changes occur in the early hours following excitotoxic exposure. Appreciable neuronal death does not become evident before $2 \mathrm{hr}$ after excitotoxin application (Dubinsky et al., 1995; Dawson et al., 1993). Full recovery of initial $\left[\mathrm{Ca}^{2+}\right]_{i}$ requires up to $2 \mathrm{hr}$ following glutamate exposure (Dubinsky, 1993). Applications of neuroprotective compounds become ineffective between 0.5 to $4 \mathrm{hr}$ following excitotoxic insult, depending upon the toxin and culture system (Hartley and Choi, 1989; Levy and Lipton, 1990; Csernansky et al., 1994). In hippocampal cultures, MK-801 and CNQX offer significant protection only when added within $2 \mathrm{hr}$ after glutamate (Dubinsky et al, 1995). Thus, the combined actions of elevated $\left[\mathrm{Ca}^{2+}\right]_{i}$ and molecular oxygen appear to be acting during a critical period during which cell fate may still be undecided.

Considering the uvershoot in oxygen tension upon reperfusion after ischemia, the contribution of oxygen-based damaging reactions may be an early step in the toxicity cascade (Silver and Erecinska, 1992). Although not all experiments have detected evidence of oxygen-based, free radical involvement in ischemic injury (Agardh et al., 1991; Lundgren et al., 1991; Folbergrova et al., 1993), some evidence exists (Cao et al., 1988; Oliver et 
al., 1990). Gradual reoxygenation after ischemia improves recovery of intracellular metabolite levels, reduces inhibition of protein synthesis, and reduces lipid peroxidation in spinal cords (Danielisova et al., 1990; Burda et al., 1991; Fercakova et al., 1992). Similarly, neuronal survival in hypoxic murine cortical cultures improves following graded reoxygenation (Sher and $\mathrm{Hu}$, 1992). Additionally, hyperoxia during reperfusion following cardiac arrest exacerbates neurological damage (Zwemer et al., 1994).

Oxygen depletion would be expected to inhibit all oxygenbased reactions; oxidative phosphorylation, oxygen-based free radical formation, and oxygen-based redox reactions. While we have no data to suggest which reactions might be contributing to excitotoxicity, oxygen-based free radicals have been implicated based upon the protection provided by free radical scavengers (Dykens et al., 1987; Monyer et al., 1990; Kinouchi et al., 1991; Clemens et al., 1993; Lafon-Cazal et al., 1993; Chow et al., 1994). Direct measurements revealed NMDA receptorlinked superoxide production 15-30 min after stimulation, associated with nitric oxide synthase activity and eventual cerebellar neuronal death (Culcasi et al., 1994). Chain reactions involving nitric oxide-stimulated superoxide, peroxynitrite, and hydroxyl radical formation may also be triggered by NMDA receptor stimulation (Dawson et al., 1993; Hammer et al., 1993; Lipton et al., 1993). Thus, the current studies are consistent with the previous experiments suggesting that oxygen-based reactions, perhaps involving free radicals, may contribute to ischemia and glutamate-induced toxic processes.

Our studies with other toxins suggest that oxygen may be essential for toxicities associated with rises in $\left[\mathrm{Ca}^{2+}\right]_{1}$. Oxygendeprivation also protected hippocampal cultures from toxicity associated with the calcium ionophore, ionomycin. Previously, bcl-2, superoxide dismutase and inhibitors of nitric oxide synthase have prevented neuronal death triggered by calcium ionophores (Dawson et al., 1993; Zhong et al., 1993), indicating that oxygen and free radical generation contribute to this type of calcium-triggered toxicity. Anoxia failed to protect hippocampal cultures from death produced by the potent external oxidants, $\mathrm{H}_{2} \mathrm{O}_{2}$ and iron sulfate. Neither of these later agents produced an immediate, transient increase in $\left[\mathrm{Ca}^{2+}\right]_{i}$. Iron did cause a progressive increase in $\left[\mathrm{Ca}^{2+}\right]_{i}$ concomitant with increased permeability of the plasma membrane. Since higher concentrations of $\mathrm{H}_{2} \mathrm{O}_{2}$ produced responses similar to iron, it is expected that the concentration used for toxicity would eventually produce a similar pattern of calcium increase at the time of plasma membrane breakdown. These results suggest that their lethality may be connected with structural damage to proteins or lipids of the plasma membrane and not a process dependent upon elevated internal calcium and oxygen-based reactions. Taken together, these experiments suggest that elevated internal calcium levels and production of intracellular oxygen-dependent events may be a potentially lethal combination.

It is unlikely that the small external alkalinization during hypoxia could possibly mediate the reported protection. External acidity decreases NMDA receptor operation in the physiological $\mathrm{pH}$ range. AMPA and kainate receptors do not show a $\mathrm{pH}-\mathrm{de}$ pendent decline in function until $\mathrm{pH}$ declines below $\mathrm{pH} 6.8$ (Traynalis and Culcandy, 1991). Thus $\mathrm{pH}$ changes in the oxygen-depleted cultures were opposite to that expected for any protective $\mathrm{pH}$ effects upon NMDA receptor function. The observed $\mathrm{pH}$ difference may reflect the imprecise nature of $\mathrm{CO}_{2}$ control in incubators compared to the more precisely mixed, bottled gas mixture used to fill the hypoxic chamber.

Whatever the mechanism, the oxygen-based step(s) in the toxicity cascade occur(s) very early after receptor stimulation during the time period when intracellular calcium remains elevated (Dubinsky, 1993). Calcium-mediated, delayed glutamate toxicity was prevented in the absence of oxygen. Thus, abnormally high elevations in $\left[\mathrm{Ca}^{2+}\right]_{i}$ were not in themselves always sufficient to cause death. Molecular oxygen appeared to be an additional, important requirement for delayed glutamate neurotoxicity.

\section{References}

Agardh CD, Zhang H, Smith Maj-Lis, Siesjo BK (1991) Free radical production and ischemic brain damage influence of postischemic oxygen tension. Int J Dev Neurosci 9: 127-138.

Benveniste H, Drejer J, Schousboe A, Diemer NH (1984) Elevation of the extracellular concentrations of glutamate and aspartate in rat hippocampus during transient intracerebral microdialysis. J Neurochem 43:1369-1374.

Burda J, Marsala M, Radonak J, Marsala J (1991) Graded postischemic reoxygenation amelierates inhibition of cerebral cortical protein synthesis in dogs. J Cereb Blood Flow Metab 11:1001-1005.

Cao W, Carney JM, Duchon A, Floyd RA, Chevion M (1988) Oxygen free radical involvement in ischemia and reperfusion injury to brain. Neurosci Lett 88:233-238.

Choi DW (1987) Ionic dependence of glutamate neurotoxicity. J Neurosci 7:369-379.

Choi DW (1990) Possible mechanisms limiting $N$-methyl-D-aspartate receptor overactivation and the therapeutic efficacy of $N$-methyl-Daspartate antagonists. Stroke 21(Suppl):20-22.

Chow HS, Lynch JJ, Rose K, Choi DW (1994) Trolox attenuates cortical neuronal injury induced by iron, ultraviolet light, glucose deprivation or AMPA. Brain Res 639:102-108.

Clemens JA, Saunder RD, Ho PP, Phebus LA, Panetta JA (1993) The antioxidant LY231617 reduces global ischemic neuronal injury in rats. Stroke 24:716-723.

Crabtree HG (1929) Observations on the carbohydrate metabolism of tumours. Biochem J 23:536-545.

Csernansky CA, Canzoniero LMT, Sensi SL, Yu SP, Choi DW (1994) Delayed application of aurintricarboxylic acid reduces glutamate-induced cortical neuronal injury. J Neurosci Res 38:101-108.

Culcasi M, Lafon-Cazal M, Pietri S, Bockaert J (1994) Glutamate receptors induce a burst of superoxide via activation of nitric-oxide synthase in arginine-depleted neurons. J Biol Chem 269:1258912593.

Danielisova V, Marsala M, Chavko M, Marsala J (1990) Postischemic hypoxia improves metabolic and functional recovery of the spinal cord. Neurology 40:1125-1129.

Dawson VL, Dawson TM, Bartley DA, Uhl GR, Snyder SH (1993) Mechanisms of nitric oxide-mediated neurotoxicity in primary brain cultures. J Neurosci 13:2651-2661.

Dubinsky JM (1992) Repeated exposure to glutamate alters both its potency and efficacy as an excitotoxin. Soc Neurosci Abstr 18:1147.

Dubinsky JM (1993) Intracellular calcium levels during the period of delayed excitotoxicity. J Neurosci 13:623-631.

Dubinsky JM, Kristal BS, Elizondo-Fournier M (1995) On the probabilistic nature of excitotoxic neuronal death. Neuropharmacology, in press.

Dykens JA, Stern A, Trenkner E (1987) Mechanism of kainate toxicity to cerebellar neurons in vitro is analogous to reperfusion tissue injury. J Neurochem 49:1222-1228

Fercakova A, Halat G, Marsala M, Lukacova N, Marsala J (1992) Graded postischemic reoxygenation reduces lipid peroxidation and reperfusion injury in the rabbit spinal cord. Brain Res 593:159-167.

Folbergrova J, Kiyota Y, Pahlmark K. Memezawa H, Smith M-L. Siesjo BK (1993) Does ischemia with reperfusion lead to oxidative damage to proteins in the brain? J Cereb Blood Flow Metab 13:145-152.

Friedman JE, Haddad GG (1993) Major differences in Ca2 $+\mathrm{i}$ response to anoxia between neonatal and adult rat $\mathrm{CA} 1$ neurons: Role of $\mathrm{Ca}^{2+}$. and $\mathrm{Na}^{+}{ }_{{ }_{0}}$. J Neurosci 13:63-72.

Friedman JE, I Iaddad GG (1994) Removal of extracellular sodium prevents anoxia-induced injuries in freshly dissociated rat CAl hippocampal neurons. Brain Res 641:57-64. 
Friel DD, Tsien RW (1994) An FCCP-sensitive $\mathrm{Ca}^{2+}$ store in bullfrog sympathetic neurons and its participation in stimulus-evoded changes in $\left[\mathrm{Ca}^{2+}\right]_{i}$. J Neurosci 14:4007-4024.

Goldberg MP, Weiss JH, Pham PC, Choi DW (1987) $N$-Methyl-D-aspartate receptors mediate hypoxic neuronal injury in cortical culture. J Pharmacol Exp Therap 243:784-791.

Goldberg MP, Monyer H, Choi DW (1988) Hypoxic neuronal injury in vitro depends on extracellular glutamine. Neurosci Lett 94:52-57.

Grynkiewicz G. Poenie M. Tsien RY (1985) A new generation of $\mathrm{Ca} 2+$ indicators with greatly improved fluorescence properties. J Biol Chem 260:3440-3450.

Hammer B, Parker WD Jr, Bennett JP Jr (1993) NMDA receptors increase $\mathrm{OH}$ radicals in vivo by using nitric oxide synthase and protein kinase C. Neuroreport 5:72-75.

Hartley M, Choi DW (1989) Delayed rescue of $N$-methyl-D-aspartate receptor-mediated neuronal injury in cortical culture. J Pharmacol Exp Ther 250:752-758.

Hartley L, Dubinsky JM (1993) Changes in intracellular pH associated with glutamate excitotoxicity. J Neurosci 13:4690-4699.

Hossmann KA, Kleihues P (1973) Reversibility of ischemic brain damage. Arch Neurol 29:375-382.

Kaku D, Goldberg MP, Choi DW (1991) Antagonism of non-NMDA receptors augments the neuroprotective effect NMDA receptor blockade in cortical cultures subjected to prolonged deprivation of oxygen and glucose. Brain Res 554:344-347.

Kass IS, Lipton P (1982) Mechanisms involved in irreversible anoxic damage to the in vitro rat hippocampal slice. J Physiol (Lond) 332: $459-472$.

Kinouchi H, Epstein C, Mizui T, Carlson E, Chen SF, Chan PH (1991) Attenuation of focal cerebral ischemic injury in transgenic mice overexpressing CuZn superoxide dismutase. Proc Natl Acad Sci USA 88: $11158-11162$.

Koh JY, Goldberg MP, Hartley M, Choi DW (1990) Non-NMDA receptor-mediated neurotoxicity in cortical culture. J Neurosci 10:693705.

Kohmura E, Yamada K, Hayakawa T, Kinoshita A, Matsumoto K, Mogami $\mathrm{H}$ (1990) Hippocampal neurons hecome more vulnerable to glutamate after subcritical hypoxia: an in vitro study. J Cereb Blood Flow Metab 10:877-884.

Lafon-Cazal M, Culcasi M, Gaven F, Pietri S, Bockaert J (1993) Nitric oxide, superoxide and peroxynitrite: putative mediators of NMDAinduced cell death in cerebellar granule cells. Neuropharmacology 32:1259-1266.

Levy DI, Lipton SA (1990) Comparison of delayed administration of competitive and uncompetitive antagonists in preventing NMDA receptor-mediated neuronal death. Neurology 40:852-855.

Lipton SA, Rosenberg PA (1994) Excitatory amino acids as a final common pathway for neurologic disorders. N Engl J Med 330:613622.

Lipton SA, Choi YB, Pan ZH, Lei SZ, Chen H-SV, Sucher NJ, Loscalzo J, Singel DJ, Stamler JS (1993) A redox-based mechanism for the neuroprotective and neurodestructive effects of nitric oxide and related nitroso-compounds. Nature 364:626-632.

Lopes-Cardozo M, Larsson OM, Schousboe A (1986) Acetoacetate and glucose as lipid precursors and energy substrates in primary cultures of astrocytes and neurons from mouse cerebral cortex. J Neurochem 46:773-778.

Lundgren J, Zhang H, Agardh CD, Smith Maj-Lis, Evans P, Halliwell B. Siesjo BK (1991) Acidosis-induced ischemic brain damage: are free radicals involved? J Cereb Blood Flow Metab 11:587-596.

Marcoux FW, Probert Albert W Jr, Weber Mark LMS (1990) Hypoxic neuronal injury in tissue culture is associated with delayed calcium accumulation. Stroke 21(Suppl):71-74.

Michaels RL, Rothman SM (1990) Glutamate neurotoxicity in vitro: antagonist pharmacology and intracellular calcium concentrations. J Neurosci 10:283-292.

Monyer H, Hartley M, Choi DW (1990) 21-Aminosteriods attenuate excitotoxic neuronal injury in cortical cell cultures. Neuron 5:121126

Monyer H, Giffard RG, Hartley DM, Dugan LL, Goldberg MP, Choi DW (1992) Oxygen or glucose deprivation-induced neuronal injury in cortical cell cultures is reduced by tetanus toxin. Neuron 8:967973

Ogura A, Miyamoto M, Kudo Y (1988) Neuronal death in vitro: parallelism between survivability of hippocampal neurons and sustained elevation of cytosolic $\mathrm{Ca}^{2+}$ after exposure to glutamate receptor agonist. Exp Brain Res 73:447-458.

Oliver CN, Starke-Reed PE, Stadtman ER, Liu GJ, Carney JM. Floyd RA (1990) Oxidative damage to brain proteins, loss of glutamine synthetase activity, and production of free radicals during ischemia reperfusion-induced injury to gerbil brain. Proc Natl Acad Sci USA 87:5144-5147.

Pauwels PJ, Opperdoes FR, Trouet A (1985) Effects of antimycin, glucose deprivation, and serum on cultures of neurons, astroscytes, and neuroblastoma cells. J Neurochem 44:143-148.

Randall RD, Thyaer SA (1992) Glutamate-induced calcium transient triggers delayed calcium overload and neurotoxicity in rat hippocampal neurons. J Neurosci 12:1882-1895.

Rothman SM (1985) The neurotoxicity of excitatory amino acids is produced by passive chloride influx. J Neurosci 5:1483-1489.

Rothman SM, Olney JW (1986) Glutamate and the patholphysiology of hypoxic-ischmic brain damage. Ann Neurol 19:105-111.

Rothman SM, Thurston JH, Hauhart RE (1987a) Delayed neurotoxicity of excitatory amino acids in vitro. Neuroscience 22:471-480.

Rothman SM, Thurston JH, Hauhart RE, Clark GD, Solomon JS (1987b) Ketamine protects hippocampal neurons from anoxia in vitro. Neuroscience 21:673-678.

Rothman SM, Yamada KA, Lancaster N (1993) Nordihydroguaiaretic acid attenuates NMDA neurotoxicity-action beyond the receptor Neuropharmacology 36:1279-1288.

Sheardown Malcolm J, Nielsen EO, Hansen AJ, Jacobsen P, Honore T (1990) 2,3-Dihydroxy-6-nitro-7-sulfamoyl-benzo(F)quinoxaline: a neuroprotectant for cerebral ischemia. Science 247:571-578.

Sher PK, Hu S (1992) Neuroprotective effects of graded reoxygenation following chronic hypoxia in neuronal cell cultures. Neuroscience 47 : 979-984.

Siesjo BK (1981) Cell damage in the brain: a speculative synthesis. J Cereb Blood Flow Meiab 1:155-185.

Silver IA, Erecinska M (1992) Ion homeostasis in rat brain in vivo: intra- and extracellular $\left[\mathrm{Ca}^{2+}\right]$ and $\left[\mathrm{H}^{+}\right]$in the hippocampus during recovery from short-term, transient ischemia. J Cereb Blood Flow Metab 12:759-772.

Tecoma ES, Monyer H, Goldberg MP, Choi DW (1989) Traumatic neuronal injury in vitro is attenuated by NMDA antagonists. Neuron $2: 1541-1545$.

Tombaugh GC, Sapolsky RM (1990) Mechanistic distinctions between excitotoxic and acidotic hippocampal damagc in an in vitro model of ischemia. J Cereb Blood Flow Metabol 10:527-535.

Traynelis SF, Cull-Candy SG (1991) Pharmacological properties and $\mathrm{H}^{1}$ sensitivity of excitatory amino acid receptor channels in rat cerebellar granule neurones. J Physiol (Lond) 433:727-763.

Vibulsreth S, Hefti F, Ginsberg MD. Dietrich WD, Busto R (1987) Astrocytes protect cultured neurons from degeneration induced by anoxia. Brain Res 422:303-311.

Werth JL, Thayer SA (1994) Mitochondria buffer physiological calcium loads in cultured rat dorsal root ganglion neurons. J Neurosci 14 348-356.

Yamada KA, Dubinsky JM, Rothman SM (1989) Quantitative phyiological characterization of a quinoxalinedione non-NMDA receptor antagonist. J Neurosci 9:3230-3236.

Yu ACH, Gregory GA, Chan PH (1989) Hypoxia-induced dysfunctions and injury of astrocytes in primary cell cultures. J Cereb Blood Flow Metab 9:20-28.

Zhang J, Dawson VL, Dawson TM, Snyder SH (1994) Nitric oxide activation of poly(ADP-ribose) synthetase in neurotoxicity. Science 263:687-689.

Zhong L, Safarian T, Kane DJ, Charles AC, Mah SP, Edwards RH, and Bredesen DE (1993) bcl-2 inhibits death of central neural cells induced by multiple agents. Proc Natl Acad Sci USA 90:4533-4537.

'Zwemer CF, Whitesall SE, D'Alecy LG (1994) Cardiopulmonary-cerebral resuscitation with $100 \%$ oxygen exacerbates neurological dysfunction following nine minutes of normothermic cardiac arrest in dogs. Resus 27:159-170. 